\title{
Liquid-Liquid Extraction of O-Cresol from O- Cresol and Water Mixture by Using Ethylene Dichloride as an Extractant
}

\author{
Suresh A Hattale \\ Department of Chemical Engineering, BVDUCOE, Pune, India
}

\begin{abstract}
Extraction is a liquid-liquid operation. It is a process of transferring a solute from one liquid phase to another immiscible or partially miscible liquid in contact with the first. The liquid- liquid extraction of $O$-Cresol and Water mixture (38.1\% $O$ - Cresol, 61.9\% water) is carried out by using Ethylene Dichloride as an extractant. Liquid-liquid extraction is a promising method to achieve high distribution coefficient with good selectivity in case of $O$-Cresol removal from $O$-Cresol and water mixture. The extraction efficiency is calculated in terms of distribution coefficient (KD) and degree of extraction (\%E).Chemical equilibrium experiments are carried to investigate the number of stages required to recover high purity and yield of $O$-Cresol by using Ethylene Dichloride. It was found that the rate of extraction increase with increases in the solvent to feed ratio. By using this process $99 \%$ pure 0 -Cresol from the bottom of distillation column can be obtained.This O-cresol can be used as a raw material for producing DMBPC \& this will also helpful in minimizing water pollution \& Also energy conservation.
\end{abstract}

Keywords: Liquid-liquid counter current Extraction, Distribution Coefficient (KD), Degree of extraction (\%E), O-Cresol, Ethylene Dichloride, Water

\section{Introduction}

\section{Liquid-Liquid Extraction}

The separation of the components of a liquid mixture by treatment with a solvent in which one or more of the desired components is preferentially soluble is known as liquidliquid extraction an operation which is used, for example, in the processing of coal tar liquids and in the production of fuels in the nuclear industry, and which has been applied extensively to the separation of hydrocarbons in the petroleum industry. In this operation, it is essential that the liquid-mixture feed and solvent are at least partially if not completely immiscible and, in essence, three stages are involved:

a) Bringing the feed mixture and the solvent into intimate contact,

b) Separation of the resulting two phases, and

c) Removal and recovery of the solvent from each phase.

It is possible to combine stages (a) and (b) into a single piece of equipment such as a column which is then operated continuously. Such an operation is known as differential contacting. Liquid-liquid extraction is also carried out in stage wise equipment, the prime example being a mixersettler unit in which the main features are the mixing of the two liquid phases by agitation, followed by settling in a separate vessel by gravity. This mixing of two liquids by agitation is of considerable importance. Extraction is in many ways complementary to distillation and is preferable in the following cases:

a) Where distillation would require excessive amounts of heat, such as, for example, when the relative volatility is near unity.

b) When the formation of azeotropes limits the degree of separation obtainable distillation.

c) When heating must be avoided. d) When the components to be separated are quite different in nature.

Important applications of liquid-liquid extraction include the separation of aromatics from kerosene-based fuel oils to improve their burning qualities and the separation of aromatics from paraffin and naphthenic compounds to improve the temperature-viscosity characteristics of lubricating oils. It may also be used to obtain, for example, relatively pure compounds such as benzene, toluene, and xylene from catalytically produced reformates in the oil industry, in the production of anhydrous acetic acid, in the extraction of phenol from coal tar liquors, and in the metallurgical and biotechnology industries.

In all extraction processes, the important feature is the selective nature of the solvent, in that the separation of compounds is based on differences in solubilities, rather than differences in volatilities as in distillation. In recent years, it has become possible to use computerised techniques to aid in the choice of a solvent with the required selectivity and to "design" appropriate molecular structures.

A recent and extremely important development lies in the application of the technique of liquid extraction to metallurgical processes. The successful development of methods for the purification of uranium fuel and for the recovery of spent fuel elements in the nuclear power industry by extraction methods, mainly based on packed, including pulsed others, the recovery of copper from acid leach liquors and subsequent electro-winning from these liquors is the most extensive, although further applications to nickel and other metals are being developed. In many of these processes, some form of chemical complex is formed between the solute and the solvent so that the kinetics of the process becomes important. The extraction operation may be either a physical operation, as discussed previously, or a 


\section{International Journal of Science and Research (IJSR) \\ ISSN (Online): 2319-7064}

Index Copernicus Value (2013): 6.14 | Impact Factor (2015): 6.391

chemical operation. Chemical operations have been classified by HANSON, as follows:

a) Those involving cation exchange such as, for example, the extraction of metals by carboxylic acids;

b) Those involving anion exchange, such as the extraction of anions involving a metal with amines, and

c) Those involving the formation of an additive compound, for example, extraction with neutral organo-phosphorus compounds. An important operation of this type is the purification of uranium from the nitrate with tri-n-butyl phosphate. This process of metal purification is of particular interest in that it involves the application of principles of both chemistry and chemical engineering and necessitates the cost evaluation of alternatives. A whole new technology with respect to extraction, developed within the last decade, has been the use of supercritical or near supercritical fluids as solvent.

In biotechnology, many of the usual organic solvents will degrade a sensitive product, such as a protein; this has led to the use of "mild" aqueous-based extractants, such as waterpolyethyleneglycol-phosphate mixtures, which will partition and concentrate the product in one of the two aqueous layers which are formed.

\section{Theory}

Solvent extraction, also called liquid-liquid extraction, can be used to separate a substance from a solution by extraction into another solvent. It can be used ether to recover a valuable substance from the original solution, or to purify the original solvent by removing an unwanted component. Examples of solvent extraction are: the extraction of uranium and plutonium salts from solution in nitric acid, in the nuclear industry; and the purification of water.

The process depends on the substance being extracted, the solute, having a greater solubility in the solvent used for the extraction than in the original feed solvent. The two solvents must be essentially immiscible. The solvents are mixed in a contactor, to effect the transfer of solute, and then the phases separated. The depleted feed solvent leaving the extractor is called the raffinate, and the solute rich extraction solvent, the extract. The solute is normally recovered from the extraction solvent, by distillation, and the extraction solvent recycled. The simplest form of extractor is a mixer-settler, which consist of an agitated tank and a decanter.The most comprehensive source of equilibrium data for liquid-liquid systems is the DECHEMA data series, Sorensen and Arlt (1979).

Depends upon following factors process can be selected,

- Feed Composition

- Economy

- Safety

\subsection{Liquid Extraction}

When separation by distillation is very difficult, liquid extraction is one of the main alternatives to consider. Close boiling mixtures or substances that cannot withstand the temperature of distillation, may often be separated by extraction. Liquid-liquid extraction also known as solvent extraction and partitioning, is a method to separate compounds based on their relative solubilities in two different immiscible liquids, usually water and an organic solvent. It is an extraction of a substance from one liquid into another liquid phase.

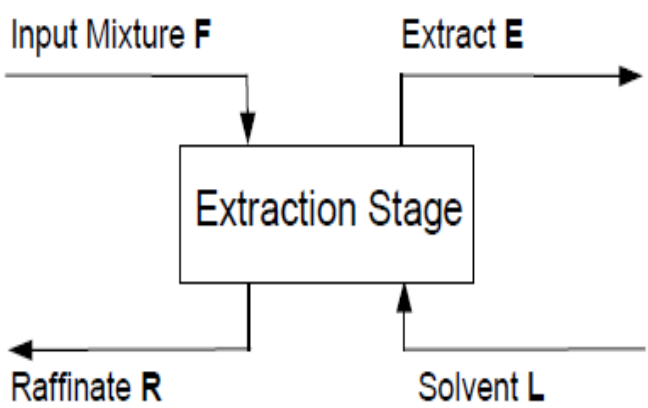

Fig. 1 Schematic representation of an extraction-stage

The solution or feed $\mathrm{F}$ to be, containing the carrier component $\mathbf{T}$ and the substance to be separated $\mathbf{C}$ (extracted component), is contacted with a defined quantity of the solvent $\mathbf{L}$. To improve the contact, the interfacial surface has to be enlarged, e.g. by dispersion. Because the ternary system $\mathbf{T}, \mathbf{L}$, and $\mathbf{C}$ forms a miscibility gap - which includes the mixture of feed and solvent, if enough solvent is added then two ternary immiscible phases are formed. Between these two phases a mass transfer will occurs. The substance $\mathbf{C}$ to be extracted is distributed between the carrier $\mathbf{T}$ and the solvent $\mathbf{L}$. The extraction substance $\mathrm{C}$ leaves the carrier $\mathrm{T}$ until the phase equilibrium between the two phases is reached. After settling the two phases, the raffinate $\mathrm{R}$, which was formed by the input mixture, is removed. The raffinate contains in the main the carrier $\mathrm{T}$ as well as a residue of the extraction substance $\mathrm{C}$ and solved solvent $\mathrm{L}$. The extractphase $\mathrm{E}$, formed by the solvent $\mathrm{L}$ contains in the main the solvent $\mathrm{L}$, the extracted substance $\mathrm{C}$ and solved carrier $\mathrm{T}$. The predefiniton of carrier $\mathrm{T}$ and raffinate $\mathrm{R}$ respective solvent $\mathrm{L}$ and extract $\mathrm{E}$ is given by the process guidelines according to figure 1 and not perforce by the substances. As mentioned in the introduction, for the same substances different processes can applied, by the exchange of carrier and solvent. In the extraction column $\mathrm{O}$ - cresol is separated from water by using EDC as a solvent. As the $\mathrm{O}-\mathrm{Cresol}$ is more soluble in EDC, It is recovered as extract phase.

\section{Experimental Material}

\subsection{Physical properties}

O-Cresol: molar mass $108.14 \mathrm{~g} / \mathrm{mol}$ and density $1.04 \mathrm{~g} / \mathrm{ml}$. Ethylene Dichloride: molar mass $98.96 \mathrm{~g} / \mathrm{mol} \mathrm{mol} \mathrm{and}$ density $1.26 \mathrm{~g} / \mathrm{ml}$.

Water: molar mass $18 \mathrm{~g} / \mathrm{mol}$ and density $1 \mathrm{~g} / \mathrm{ml}$.

\subsection{Experimental Procedure}

\subsubsection{For Raffinate phase}

1) Take 7 conical flasks and no. them as $1,2 \ldots 7$.

2) Take $30 \mathrm{ml}$ water in each flask add 0, 6, 12, 18,24,30,36 $\mathrm{ml}$ of EDC respectively in flask no. $1,2,3 \ldots .7$. 


\section{International Journal of Science and Research (IJSR) \\ ISSN (Online): 2319-7064}

Index Copernicus Value (2013): 6.14 | Impact Factor (2015): 6.391

3) Measure the volume of o-cresol consumed in burette till the turbid solution is formed in the conical flask.

4) Note down the volume of o-cresol required in each flask.

5) Find out the composition of three component mixture present in conical flask.

6) Plot the composition on a triangular plot as raffinate curve.

\subsubsection{For extract phase}

1) Take 7 conical flasks and no. them as $1,2 \ldots 7$.

2) Take $30 \mathrm{ml}$ o-cresol in each flask add $0,6,12$, $18,24,30,36 \mathrm{ml}$ of EDC respectively in flask no.1, 2, $3 \ldots .7$.

3) Measure the volume of water consumed in burette till the turbid solution is formed in the conical flask.

4) Note down the volume of water required in each flask.

5) Find out the composition of three component mixture present in conical flask.

6) Plot the composition on a triangular plot as an extract curve.

\subsection{Experimental Data}

For Plotting the "BINODAL CURVE" the Raffinate \& Extract Phase Data should be needed. The following data is generated from "VOLUMETRIC TITRATION" .

Table No. 6.1 Raffinate \& Extract phase

$\mathrm{A}=$ Water, $\mathrm{B}=\mathrm{EDC}, \mathrm{C}=\mathrm{O}-\mathrm{Cresol}$.

Extract Phase Data (wt. \% basis)

Raffinate Phase Data (wt. \% basis)-

Table 3.1

\begin{tabular}{|c|c|c|c|c|c|c|c|c|c|}
\hline Sr. & A & C & B & \multicolumn{4}{|c|}{} & \multicolumn{3}{|c|}{ Mass fraction } \\
No. & In & B.R in & In & \multicolumn{3}{|c|}{ Weight in gm } & \multicolumn{3}{|c|}{ Ma } \\
\cline { 5 - 10 } & ML & ML & ML & A & C & B & \%A & \% C & \% B \\
\hline 1 & 30 & 0.97 & 0 & 30 & 1.02 & 0 & 3.20 & 96.88 & 00.00 \\
\hline 2 & 30 & 1.718 & 6 & 30 & 1.80 & 7.518 & 9.59 & 74.84 & 15.57 \\
\hline 3 & 30 & 11.13 & 12 & 30 & 11.69 & 15.03 & 20.62 & 56.06 & 23.32 \\
\hline 4 & 30 & 20.76 & 18 & 30 & 21.8 & 22.55 & 29.32 & 43.52 & 27.16 \\
\hline 5 & 30 & 28.97 & 24 & 30 & 30.42 & 30.07 & 33.67 & 36.21 & 30.12 \\
\hline 6 & 30 & 36.64 & 30 & 30 & 38.48 & 37.59 & 36.28 & 31.24 & 32.49 \\
\hline
\end{tabular}

Table 3.2

\begin{tabular}{|c|c|c|c|c|c|c|c|c|c|}
\hline & & & \multirow{3}{*}{\begin{tabular}{|c|} 
B \\
In \\
ML
\end{tabular}} & \multirow{2}{*}{\multicolumn{3}{|c|}{ Weight in gm }} & \multirow{2}{*}{\multicolumn{3}{|c|}{ Mass fraction }} \\
\hline \multirow{2}{*}{$\begin{array}{l}\text { Sr. } \\
\text { No. }\end{array}$} & \multirow[t]{2}{*}{\begin{tabular}{|c|}
$\mathrm{A}$ \\
$\mathrm{In} \mathrm{ML}$
\end{tabular}} & \multirow{2}{*}{$\begin{array}{c}\mathrm{C} \\
\text { B.R in } \\
\mathrm{ML}\end{array}$} & & & & & & & \\
\hline & & & & A & $\mathrm{C}$ & B & $\% \mathrm{~A}$ & $\% \mathrm{C}$ & $\% \mathrm{~B}$ \\
\hline 1 & 1.35 & 30 & 0 & 1.35 & 31.5 & 0 & 4.12 & 95.88 & 0 \\
\hline 2 & 2.78 & 30 & 6 & 2.78 & 31.5 & 7.51 & 6.66 & 79.93 & 12.89 \\
\hline 3 & 4.87 & 30 & 12 & 4.87 & 31.5 & 15.03 & 9.48 & 67.78 & 22.74 \\
\hline 4 & 6.32 & 30 & 18 & 6.32 & 31.5 & 22.55 & 10.56 & 59.50 & 29.94 \\
\hline 5 & 10.00 & 30 & 24 & 10.00 & 31.5 & 30.07 & 13.98 & \begin{tabular}{|l|}
51.48 \\
\end{tabular} & 34.54 \\
\hline 6 & 21.81 & 30 & 30 & 21.81 & 31.5 & 37.59 & 24 & 41.33 & 34.67 \\
\hline
\end{tabular}

\section{Extraction Column Design}

\subsection{Factor needed for selection of extractor}

Following Factors are needed,

- The No. of Stages Required

- The Throughputs

- The Settling Characteristics of Phases

- The available Floor Area \& Head Room

\subsection{Design Calculation}
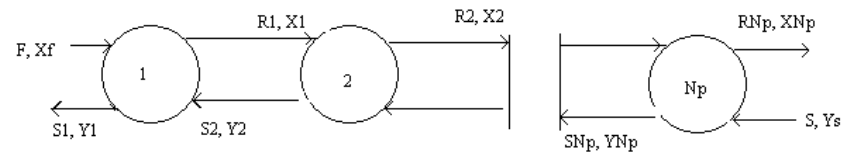

Fig. Countercurrent Multistage Extraction

Material Balance over Extractor

At Steady State,
From Above Fig.

$$
\mathrm{F}+\mathrm{S}=\mathrm{S} 1+\mathrm{RNp}=\mathrm{M}
$$

\subsection{Mass balance for the counter current extraction}

1. stage

1. to 2 . stage

1. to n-th stage

$$
\begin{aligned}
\mathrm{m}_{\mathrm{F}}+\mathrm{m}_{\mathrm{E} 2} & =\mathrm{m}_{\mathrm{R} 1}+\mathrm{m}_{\mathrm{E} 1} \\
\mathrm{~m}_{\mathrm{R} 1}-\mathrm{m}_{\mathrm{E} 2} & =\mathrm{m}_{\mathrm{F}}-\mathrm{m}_{\mathrm{E} 1}=\mathrm{Q} \\
\mathrm{m}_{\mathrm{R} 2}-\mathrm{m}_{\mathrm{E} 3} & =\mathrm{m}_{\mathrm{F}}-\mathrm{m}_{\mathrm{E} 1}=\mathrm{Q} \\
& \vdots \\
\mathrm{m}_{\mathrm{Rn}}-\mathrm{m}_{\mathrm{L}} & =\mathrm{m}_{\mathrm{F}}-\mathrm{m}_{\mathrm{E} 1}=\mathrm{Q}
\end{aligned}
$$

According to these equations one can define for every stage a constant mass-difference-stream $\mathrm{Q}$, which is equal to the difference between the feed and the extract of the first stage. Every balance-equation (5) to (7) is, according to the mixture law, a line in the triangular diagram. For every stage $\mathrm{I}$, the line cuts the point for the leaving raffinate $\mathrm{R} i$ and the incoming extract $\mathrm{E} \mathrm{i}+1$ (for the $\mathrm{n}$-th stage, the solvent $\mathrm{L}$ ). The lines for all $\mathrm{n}$ stages meet also in one fixed point $\mathrm{Q}$, which is therefore called pole or working-point

Usually the position of the pole $\mathrm{Q}$ is outside the diagram (right or left, depending on the position of F end E1) and represents only a fictional composition, because negative amounts and negative concentration don't exist. One can't have a real association of this composition due to it is only a fictional mixture, which is mathematically founded in the equations mentioned above.

The position of $\mathrm{Q}$ can be determined if the concentrations are known or demanded:

- The feed $\mathrm{F}$ in the first stage

- The leaving extract in the first stage

- The leaving raffinate in $n$-th stage, determined by the problem

- The solvent incoming to the last stage (usually pure solvent)

\subsection{Stage Calculation for Extraction Column by using} binodal curve 


\section{International Journal of Science and Research (IJSR)}

ISSN (Online): 2319-7064

Index Copernicus Value (2013): 6.14 | Impact Factor (2015): 6.391

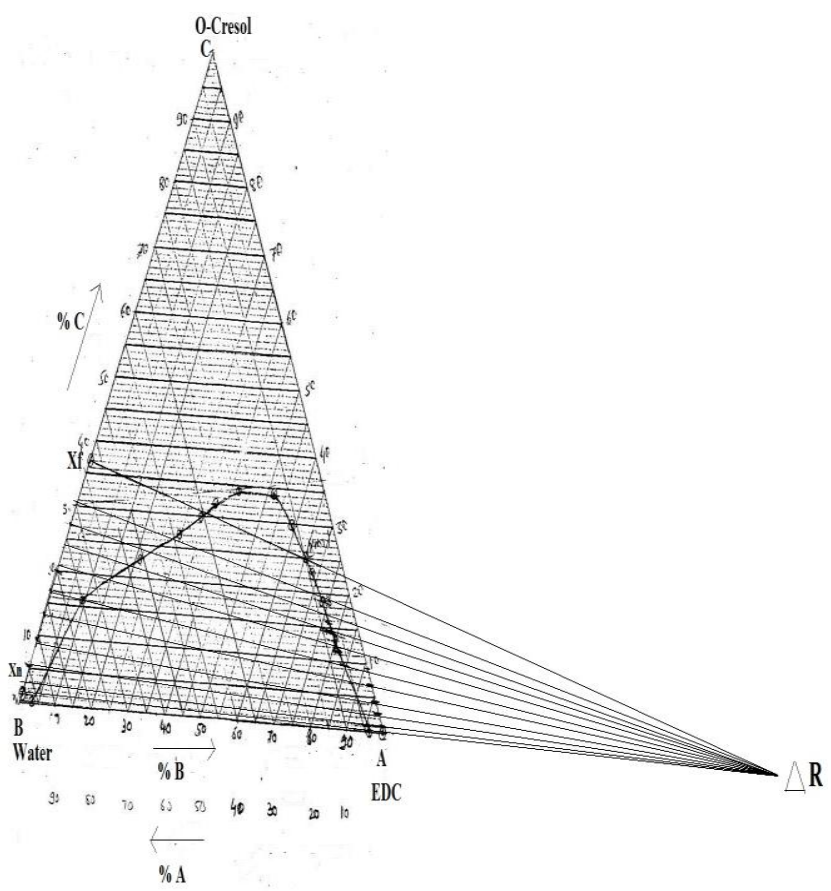

Figure 4.2: Stage calculation

\subsection{Process design of Extraction Column result}

- No. of stages required for $99 \%$ recovery of O- Cresol $($ theoretical $)=10$

- Solvent to Feed ratio (based on composition) $=2$

- Recovery of O- Cresol by experiment $=96 \%$

\section{Experimental Result And Discussion}

The chemical equilibrium isotherms for liquid-liquid extraction of o-cresol from mixture of o-cresol and water with ethylene dichloride as a solvent. Distribution coefficient $(\mathrm{KD})$ of O-cresol and Ethylene Dichloride was good and with recovery of o-cresol (\%of 85.5,90 - 96 at different solvent to feed ratio), range from 1.0,1.5 to 2.0 of o-cresol. At solvent to feed ratio 2.0, highest recovery of ocresol $96 \%$ is achieved at room temperature. It was found that if Solvent to feed ratio increases, the recovery of ocresol is increases.

Table No. 4.1

\begin{tabular}{|c|c|c|}
\hline $\begin{array}{c}\text { Flask } \\
\text { No. }\end{array}$ & ml collected & $\begin{array}{c}\text { conc. of O-Cresol in ml } \\
\text { (measured in HPLC) }\end{array}$ \\
\hline $\mathbf{V}_{\mathbf{1}}$ & 31.5 & 29.47 \\
\hline $\mathbf{V}_{\mathbf{2}}$ & 10.0 & 2.78 \\
\hline $\mathbf{V}_{\mathbf{3}}$ & 7.5 & 1.10 \\
\hline $\mathbf{V}_{\mathbf{4}}$ & 7.4 & 0.4654 \\
\hline $\mathbf{V}_{\mathbf{5}}$ & 7.2 & 0.038 \\
\hline $\mathbf{V}_{\mathbf{6}}$ & 7.0 & 0.0294 \\
\hline $\mathbf{V}_{\mathbf{7}}$ & 7.7 & 0.0161 \\
\hline $\mathbf{V}_{\mathbf{8}}$ & 7.2 & 0.01152 \\
\hline $\mathbf{V}_{\mathbf{9}}$ & 7.1 & 0.00512 \\
\hline $\mathbf{V}_{\mathbf{1 0}}$ & 7.4 & 0.00296 \\
\hline Total & 99 & $\sum 32.33$ \\
\hline
\end{tabular}

$\%$ Recovery $($ experimental $)=(36.92 / 38.1) * 100=96 \%$

\section{Conclusion}

The advanced Extraction Process can be used in many of the industries. To reduce pollution, load on ETP this type of advanced extraction process is used. The extraction process is compatible with various unit operations. For increasing the profit, many of industries use this method.

The liquid-liquid extraction of o-cresol and water with Sodium hydroxide was studied. Distribution coefficient (KD) of O-cresol and Ethylene Dichloride was good and with recovery of o-cresol (\% of 85.5,90 - 96 at different solvent to feed ratio), range from $1.0,1.5$ to 2.0 of o-cresol. At solvent to feed ratio 2.0, highest recovery of o-cresol $96 \%$ is achieved at room temperature. It was found that if Solvent to feed ratio increases, the recovery of o-cresol is increases.

\section{References}

[1] Ullmann's Encyclopedia of Industrial Chemistry, 5th Edition, Volume B3 Unit operations II", Chapter „Liquid-liquid extraction“, VCH Verlagsgesellschaft mbH, Weinheim, 1988 Ullmanns Encyklopädie der technischen Chemie, 4.Auflage,Band 2 „Verfahrenstechnik

I,Grundoperationen“,Kapitel,,Flüssig-flüssig-Extraktion“, Verlag Chemie, Weinheim, 1972

[2] Gmehling, J.; Brehm, A.: „Lehrbuch der Technischen Chemie“, Band 2 „Grundoperationen“, Georg Thieme Verlag, Stuttgart, 1996

[3] Sattler,K.:,ThermischeTrennverfahren“, Verlagsgesellschaft mbH, Weinheim, 1995

[4] Schlünder,E.,Thurner,F.,

$\mathrm{VCH}$ Absorption,Extraktion",Georg Thieme Verlag, Stuttgart, 1986

[5] Sørensen, J. M.; Arlt, W.: „Liquid-liquid equilibrium data collection", Chemistry Data Series, Vol. V, DECHEMA Frankfurt am Main, ab 1979

[6] Lohmann, J.; Joh, R.; Nienhaus, B,; Gmehling, J.: „Verbesserung der Vorhersagequalität und Erweiterung der Anwendungsgebiete der Gruppenbeitragsmethode Modified UNIFAC (Dortmund)", Chem. Ing. Tech. 70 (1998) 138-142

[7] Welzenbacher,U.Neue Datenblätter für gefährliche Arbeitsstoffe nach der Gefahrstoffverordnung“, WEKA Verlag, Augsburg 1994 